\section{The 19th Santa Fe Symposium on Jewellery Manufacturing Technology}

\author{
Mark Grimwade \\ Consultant, UK
}

The 19th Annual Santa Fe Symposium on Jewellery Manufacturing Technology was held on 22-25 May 2005 at Albuquerque, New Mexico, USA. The Symposium was dedicated to the memories of Roland Loewen, a frequent contributor to past Symposia and author of the book Small Scale Refining of Jewelry Wastes, and lader Milani of Pro Gold, Italy. Twenty-four papers were presented over three and a half days on a variety of subjects of relevance to the industry. There were 131 registered attendees with representatives from 13 countries.

Andrea Hill, Director, The Bell Group Inc., USA gave the opening Keynote Address on the first morning. Her theme was "Innovation - How to Remain Competitive in Products, Processing and Organisation".

\section{An Introduction to Metallurgy Part IV - Odds and Ends}

Mark Grimwade, Consultant to the Worshipful Company of Goldsmiths, UK.

Because there were some topics that did not fall readily under the headings of Parts I-III of this series, this presentation highlighted the metallurgical principles and mechanisms underlying three such topics, namely, Soldering and Brazing, Corrosion and Stress Corrosion and Tarnishing of Carat Gold and Silver Alloys. The first included the requirements for successful soldered joints, e.g. wettability, capillary attraction, metallurgical compatibility between the solder alloy and the parent metal(s) being joined, joint gap, length and area and configuration. The chemical and corrosive behaviour of gold, silver and their alloys were briefly discussed and the causes of stress corrosion in low carat golds were explained. Finally, the factors affecting the tarnishing behaviour in silver and its alloys and the carat golds were reviewed.

\section{Standardizing the Designation of Karated Gold Solders}

Greg Todd, Stuller Inc., USA.

Problems have existed concerning the designation of carat gold solders in terms of their melting range characteristics, i.e. 'easy', 'medium', ‘hard', etc. for each colour and caratage of gold. Different manufacturers of solder products have their own designations and there is no uniformity across the board. Using differential thermal analysis, the melting ranges were established for twenty-five 10, 14 and 18 ct yellow and white gold alloys and 129 commercial solder compositions from four different manufacturers. The data were used to define the solder grade designations in terms of temperature so that manufacturers will be able to ensure consistency of solder alloy descriptions throughout the industry.

\section{Jewelry Alloy Hardening and Hardness Testing}

Gary Dawson with Andrew Nyce and Stewart Grice, Goldworks, USA.

After a brief review of annealing, precipitation hardening and the disorder-order transformation in the heat treatment of carat gold alloys, the Speaker went on to describe and discuss a simple and inexpensive test for determining the relative hardness of alloys given various heat treatments that could be used by a bench jeweller. This consisted of a drop tube sited above the test sample. Three different types of punches were dropped from a standard height onto the sample and the diameters of the resulting indentations measured. Data is presented for alloys in the annealed, heat treated and cold rolled conditions and, in some cases, compared with Vickers Hardness data. The results were consistent with the changes in hardness expected for the various conditions. In addition, a simple abrasive wear test using a barrel tumbler containing abrasive media was developed. Age hardening was shown to significantly increase wear resistance for cast and heat treated sterling silver rings.

\section{Understanding Microalloys}

John E. Bernadin, Pure Gold Inc., USA.

Pure precious metals are too soft to make jewellery. However, this presentation showed that it is possible to microalloy gold, silver and platinum by adding certain elements to increase strength and hardness whilst retaining a precious metal content of not less than 997/1000 fineness. The important criteria are that the added elements are soluble in the pure metal at high temperature and that they have limited solubility at low temperature thereby allowing precipitation hardening. The effects of overaging, cold work, joining, casting and finishing on the properties of microalloys were discussed. The hardness of 998.5 fineness microalloyed gold can be increased to about $185 \mathrm{HV}$ by a combination of solution treatment, ageing, cold work and further ageing. 
Similar results were obtained with 998.6 fineness silver and 997 fineness platinum. It is possible also to achieve further increases in strength and properties by adding these microalloying elements to sterling silver and carat gold alloys.

\section{Continuous Casting of Jewellery Alloys}

Dr. Christopher Corti, Consultant to the World Gold Council and the Goldsmiths' Company, and Peter Taylor, The Goldsmiths' Company, UK.

Continuous casting of the precious metals and their alloys is widely used in the jewellery industry for the production of semi-finished mill products. Advantages compared with the older traditional method of static ingot casting are improved product yield, metallurgical quality, lower energy consumption and reduced production costs in labour and time. Dr Corti reviewed the history and principles and commercial practice of continuous casting paying particular attention to the equipment used for the precious metals, such as crucible and mould (die) materials and design, casting mode, etc. Factors affecting the process and product quality were discussed with reference to casting carat gold alloys and silver and its alloys. Finally, information was given concerning some of the more well-known continuous casting machines that are available to jewellery manufacturers.

\section{Designing, Building and Testing a Thermal Expansion Torque Plate System for Diffusion-Bonding Mokumé Gane Billets}

James Binnion, James Binnion Metal Arts, Andrew Nyce, Andrew Nyce Designs, and Stewart Grice, Hoover \& Strong Inc., USA.

James Binnion has presented papers at past Symposia on the manufacture of Mokumé Gane. This is the traditional Japanese metalworking technique of diffusion bonding multiple layers of dissimilar metals to produce a billet that can be further processed and patterned to give a desired 'wood grain' effect. The torque plate and bolt system that he has used to produce the laminated billets has had limitations

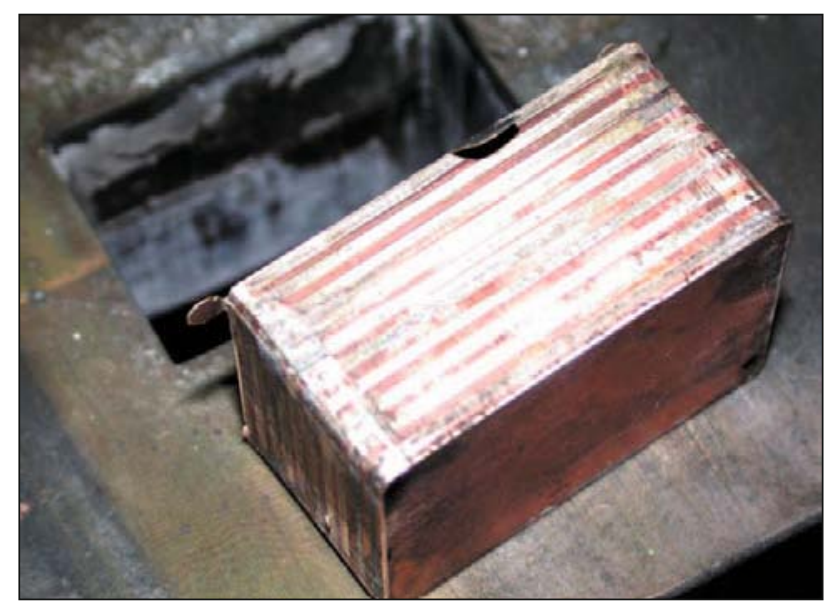

Mokumé-Gane billet that has been laminated in the TEMTP die and in this paper he describes in considerable detail a new thermal expansion mismatch torque plate system (TEMTP) designed to overcome such problems. Harness and tensile tests were performed on bonded 14 ct yellow, red and palladium-white golds and the metallography of the diffusion-bonded zones was examined.

\section{Basic Techniques for the Sintering Process for Jewellery and Multi-Colour Rings}

Klaus Wiesner, C Hafner GnbH Gold and Silver Refining, Germany.

There has been considerable interest recently in multicolour jewellery produced from combinations of different coloured metals and alloys. The speaker began by reviewing the various production techniques used for making these combinations before going on to discuss in some detail the principles and metallurgical basics of sintering, diffusion bonding and pressure welding technologies. The preparation of the individual parts to be bonded in terms of microstructure and surface cleanliness is an important part of the process. Bonding is achieved by hot pressing using either resistance- or inductively-heated machines. Important processing parameters are heating and cooling rates, temperature, time, pressure and atmosphere. Results were presented for a wide range of combinations of precious and non-precious metals.

It is true that sintering is a diffusion bonding mechanism but it is usually confined to particulate materials, e.g. metal powders. Powder metallurgy was not used in this work and this reviewer believes that diffusion bonding is a better description and avoids confusion.

\section{Computer Simulation and Jewellery Production}

Dr. John Wright, Consultant, UK.

Computer simulation is a powerful analytical tool for research, exploring designs and developing production prototypes. Real casting trials with several sets of operating parameters and 300-400g of precious metal in each cast is

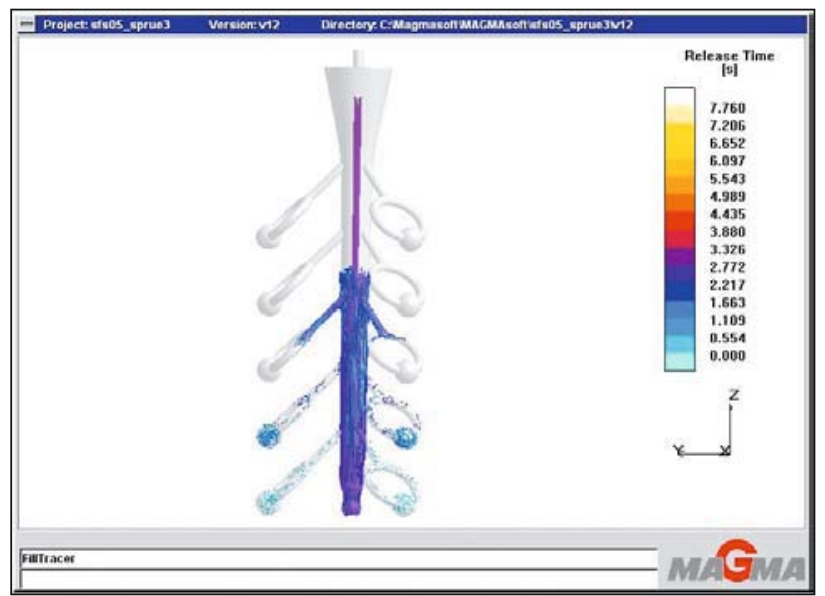

Modelling of investment casting: Filling of mould with metal 


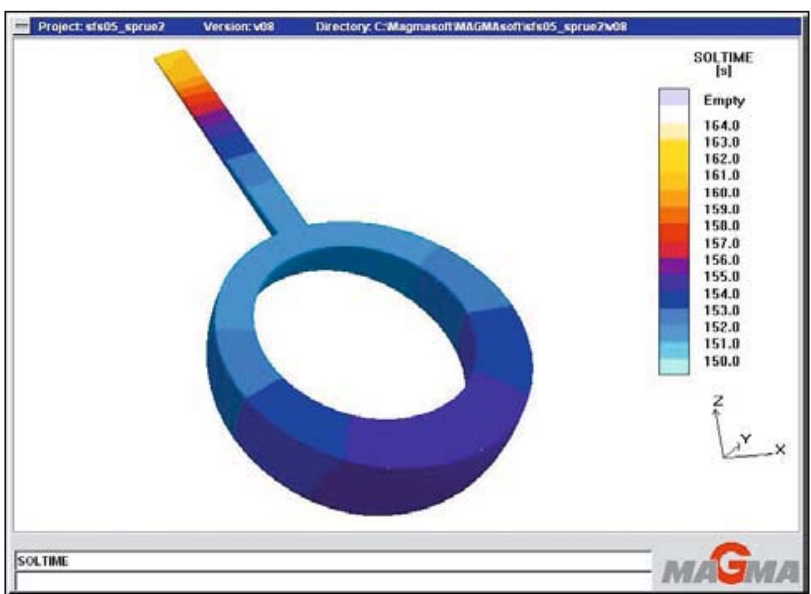

Modelling of investment casting: Solidification of ring

an expensive and time-consuming business and much of this can be overcome by simulating the process. Complex finite element analysis (FEA) software, e.g. MagmaSoft, is used to create the simulation model. One input to the FEA is a CADgenerated design. The other input is the physical and thermal data for the mould material and the casting alloy. The problems here are in obtaining sufficiently accurate data at the casting temperature and the fact that jewellery castings are small and relatively lightweight with a high surface area to volume ratio. Sensitivity analysis assists in indicating which variables need to be estimated as accurately as possible for data input. The simulation model is used to demonstrate the filling and solidification in a mould in slow motion and assists in understanding the complexities of the process. Ideally, the simulation model should be calibrated by using real-time measurements from a typical casting operation. Eventually, this could lead to building a database for jewellery casters.

\section{Computer Simulation of Investment Casting}

Dr. Jörg Fischer-Bühner, The Research Institute for Precious Metals (FEM), Germany.

This is an EU-funded project on the computer modelling of the investment casting of sterling silver. The computer simulation results were tested by comparison with actual casting of silver trees and the agreement was remarkable. Information was obtained on many aspects, e.g. how the mould fills and solidifies, gating and spruing effects, flask and metal temperature changes, time to solidify and shrinkage. It was fascinating to see these effects demonstrated by slow motion computer animation. There is no doubt that simulation modelling offers a powerful technique for understanding the casting process and avoiding defects such as shrinkage porosity.

\section{Using Surface Area to Volume Ratio to Determine the Quality of Castings - Part II}

Tino Volpe, Technical Manager, Tiffany \& Co., USA.

The results given in Part I of this study (see the 18th Symposium) were clouded by the system temperatures being too high. Almost all the castings were poor regardless of the Volume/Area (V/A) ratio. This time, lower temperatures were used and the effect of several gating shapes and sizes was investigated. A 'Design of Experiments' procedure was used to study the effects of flask and metal temperatures on one casting shape and size, namely a cube of fixed V/A ratio. Three gating configurations with different V/A ratios were used, one that was obviously too small, a second that was similar to that used for a production casting and the third that was an 'ideal' gate based on Chvorinov's Rule. While it is true that V/A for the part being cast is a guide to size the gate, the overriding factor is the influence of system temperature. The 'ideal' gate allows one to cast at much lower temperatures allowing less metal-mould reaction and wear and tear on casting equipment.

\section{Innovative Lost Wax Investment Casting Technique}

Dr. K. D. Desai, Technical Advisor, Livingstones Group, Mumbai, India.

This presentation dealt with the development of an innovative method for reducing the burnout cycle time and energy costs by $60 \%$. The normal procedure for designing the wax tree is modified by providing return vents from each wax piece back towards the tree base. At $540^{\circ} \mathrm{C}$ during burnout, a hot air jet flow is used to remove the carbonised wax residues and sulphurous gases. The final temperature is $640^{\circ} \mathrm{C}$ which is considerably lower than normal and helps to protect precious stones in the case of stone-in-place casting. The removal of gas is less dependent on the permeability of the investment. There is a considerable reduction in gas porosity coupled with an improved microstructure, strength and wear resistance in the castings. In addition, Dr. Desai demonstrated a significant reduction in metal loss due to smooth filling and a better surface finish.

\section{Thermal Stability and Chemical and Physical Features of Gypsum-bonded Investment with Regard to the Burnout Cycle}

Dr. G. M. Ingo et al, Consiglio Nazionale delle Richerche, Italy. A number of investigative techniques have been used to study the effect of the burnout cycle temperature and duration on the mechanical properties and thermal stability of the investment. The following conclusions were drawn from the results given in the presentation. Burnout at low temperature, e.g. $500^{\circ} \mathrm{C}$, leads to moulds with porosity and relatively low strength. Short burnout at $600^{\circ} \mathrm{C}$ gives the 
highest thermal stability and strength compared with the normal of $720^{\circ} \mathrm{C}$ for 5 hours. However, the temperature is too low to ensure complete removal of wax residues that also catalyse gypsum decomposition during casting with an attendant increase in gas porosity. The temperature of $600^{\circ} \mathrm{C}$ could only be used with selected waxes that can burn out completely at this temperature. The results show that it is possible to tailor the final chemical/physical properties of a gypsum-bonded investment by properly selecting the burnout cycle parameters.

\section{The Role of Silicon in Investment Casting - A Study of the Reactivity of Various Metals with the Investment}

Daniele Maggian et al, Pro Gold s.r.l., Italy.

Silicon is added to carat gold alloys for casting as it improves mould filling together with giving a deoxidised finish on the castings. It has been thought previously that the formation of silica, $\mathrm{SiO}_{2}$ was responsible for these effects. Results from a detailed and lengthy experimental programme on a 14 carat yellow gold alloy with varying copper and zinc contents and with or without a silicon addition suggest that silicon forms a silicate compound from the liquid phase. This then forms a thin film on the surface of the molten metal inhibiting the evaporation of zinc and other metals and minimising the contact of these metals with the mould wall. It is presumed that the metal-mould reactions are reduced and the flow of molten metal on the mould wall is facilitated.

\section{The Preparation of the Master Mould - The Key Point of Stone-in-Place Casting}

Dr. Hubert Schuster, Jewelry Technology Institute and Alberto Bolzonella, High Prototyping, Italy.

The most important stage for successful stone-in-place casting is the preparation of the master model. This leads to an easy, fast, precise and safe stone setting and ultimately to a top quality final product. Dr. Schuster described the key actions that have to be taken for different types of settings and model-making systems, i.e. wax, metal, CAD/CAM, and the preparation of the master model for wax setting. He discussed also the reliability of stone-in-place casting compared to traditional setting and the risks involved in damaging the stones.

\section{CAD Software for Jewelry Design: A Comprehensive Survey}

Scott Patrick, Rio Grande, USA.

This was an excellent review of CAD technology. It dealt first with the terminology and the advantages of CAD/CAM compared with the traditional methods of design and modelmaking. The distinction was drawn between parametric modelling and NURBS modelling. In the former, a series of steps that are parameter driven builds up the design. The designer can make changes to the parameters of dimension and the relationship to individual features of the design. The latter is surface rather than solid modelling and the basis is the curve. Objects can be reshaped at will and this allows for a greater freedom of design. The Speaker reviewed some of the CAD software that is available in the market and compared their cost, ease of learning and user-friendliness.

\section{The Revolution of CAD/CAM in the Casting of Fine Jewelry}

Steven Adler, Automated 3D Modeling Inc., USA.

This paper compared the advantages of different Rapid Prototyping (RP) manufacturing methods and focused on the new machine technologies available for producing jewelleryquality models. The terminology of stereolithography (STL) was explained and the way in which layered models are built up from the STL format data described. Four of the leading Rapid Prototyping Systems were discussed and compared. Finally, consideration was given to the relationship between the RP technologies and the investment casting process. Experimental data were given for patterns produced by RP machines for a particular ring design. Materials, shrinkage rates, thermal expansion, burnout parameters and surface treatments were all assessed when comparing the RP methods.

\section{CAD/CAM - Hints, Tips and Observations}

Apollonius Nooten-Boom II, Hean Studio Ltd., UK.

This excellent presentation looked at CAD/CAM from the point of view of the user. It first discussed the problems of

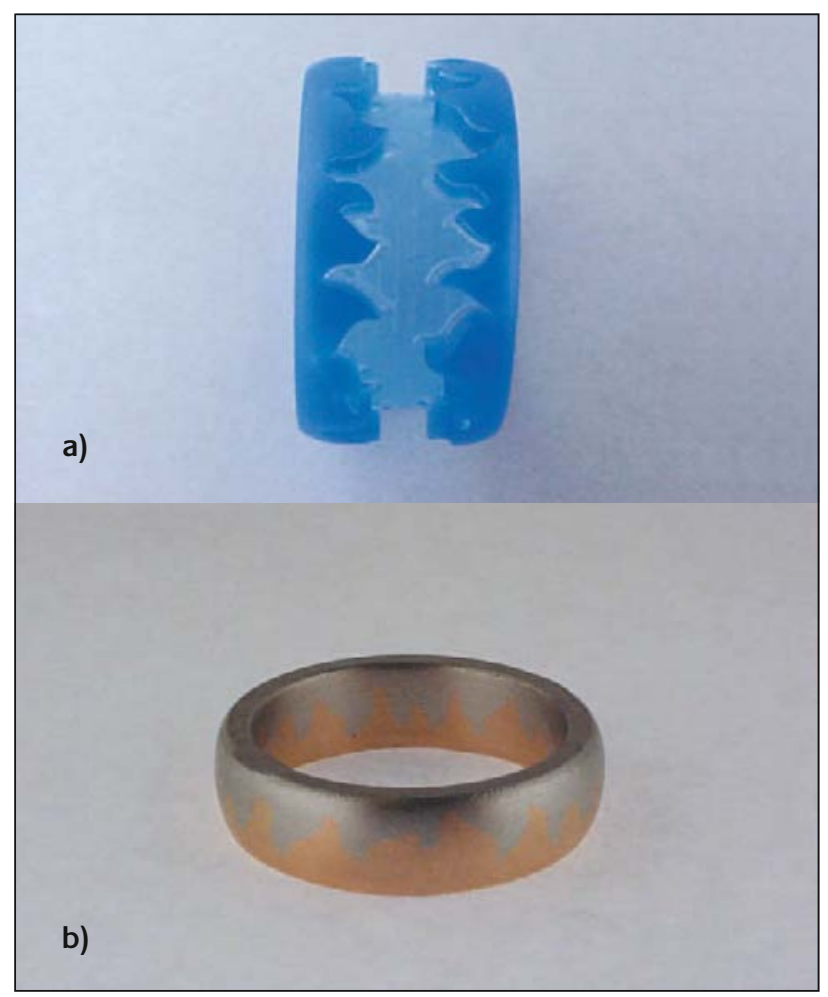

a) Machined wax of 'Flame Ring', b) Finished ring 
visual scale from large scale images on the screen to actualsize product and these were illustrated with practical examples. Consideration has to be given to the on-screen measurements in order to achieve the desired dimensions on the finished product. The second part of the paper looked at some of the practical problems in CNC machining of the wax patterns. The Speaker considers that CNC technologies still have many advantages over the wax- and resin-build RP technologies. It is recommended those potential users of CAD/CAM software and CNC machining should read this paper.

\section{Arthritic Finger Joints and Adjustable Ring}

Fred Klotz, Hoover \& Strong, USA.

The medical causes of swollen finger joints due to arthritis were reviewed and the need to provide some type of adjustable ring shank for sufferers of this condition were discussed. After describing the gauges used for measuring ring size at the point of wear on the finger, the historical methods adopted to deal with the problem were explored. Various types of adjustable shanks have been successfully marketed over the last 50 years and the ingenious and unique mechanisms of each type were explained.

\section{Photographic Images on Metal Substrates - Taking the Mystery out of Subliminal Jewelry}

Steven Alviti, Bel Air Finishing Supply, USA.

This paper explored the methods by which photographic and/or computer-generated images can be applied to metal substrates for jewellery applications. Sublimation printing is the process of printing an image onto a photographic paper using a special ink. The paper is then placed against a metal substrate coated with a polymer designed to accept the dye that is sublimated from the image on the paper into the polymer under the application of heat and pressure.

\section{Putting Quality Management at Work in Jewellery Workshops}

Alexandre Auberson, Cartier Joaillerie International, France. Quality management systems such as IS09001 are quite common, if not compulsory, in many industrial organisations. Even medium and large jewellery manufacturers have adopted such systems but the apparent administrative drawbacks may act as a deterrent to smaller companies. This paper highlighted some proven methods for improving the quality of products. These were illustrated with examples from jewellery production.

\section{Quality Control: Actual Quality and Perceived Quality}

Dr. Valerio Faccenda and Michele Condo, Pomellato S.p.A., Italy.

Customer complaints over a four-year period have been examined by Pomellato. Dr. Faccenda discussed the results of the investigation and concluded that manufacturers should regularly promote the spread of information on the properties and correct use of jewellery products among consumers. The most common problems encountered in the feedback from the market are tarnishing of silver jewellery, white gold that turns yellow, stains on skin and clothing, mercury contamination, wear and tear, loose or lost gemstones and the damage that can be due to cleaning in 'wonder' solutions. The causes of each problem were explained. It should be mentioned that the percentage of complaints was extremely small compared to the number of items produced and only a few cases could be attributed to manufacturing.

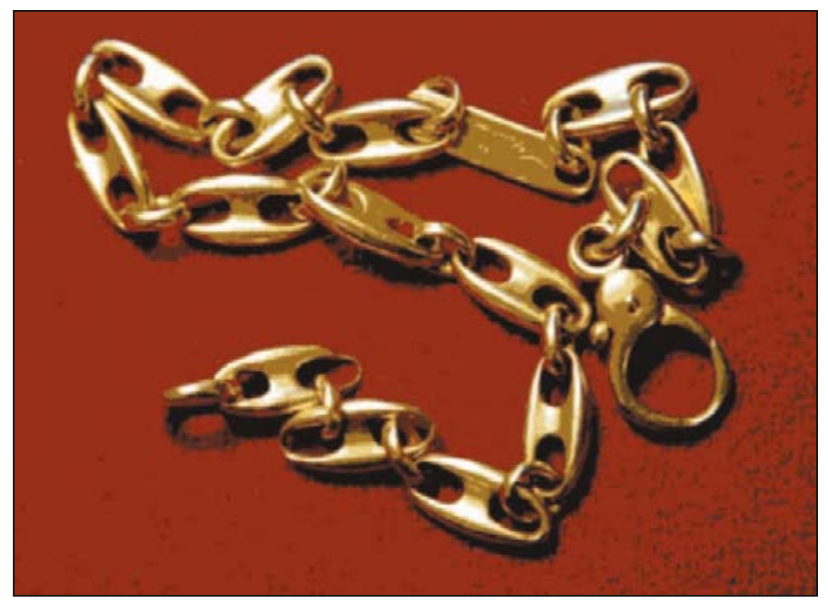

Investment cast 18 carat yellow gold bracelet after 2 years wear; note worn links. These parts are softer due to time differences in water quenching of flasks

\section{Laser Bending of Silver}

Dr. Sarah Silve and H. Zhao, Brunel University, UK.

Following her presentation at last year's Symposium, Dr. Silve reported the latest progress on using a $\mathrm{CO}_{2}$ laser to bend silver to produce shaped sheet metal products. Experimental data collected from thermocouples employed to measure the temperature gradients that generate the bending together with a study of the effects of beam line energy, diameter and velocity of traverse allowed a more accurate selection of the operating parameters for bending both conventional sterling silver and the silver-germanium alloy now being marketed as 'Argentium'. 


\section{Platinum Alloys: Features and Benefits}

Jurgen Maerz, Platinum Guild International, USA.

Many of the problems identified with platinum jewellery can be traced back to the use of the wrong alloy. This is particularly true of rings that can suffer from scratches, dents and distortion. This paper discussed the properties of the various platinum alloys available on the market and their suitability for jewellery applications.

\section{Awards}

Research awards were given to Jõrg Fischer-Bühner, Andrea Basso and Stewart Grice. Jörg Fischer-Bühner and Stewart Grice were also given Ambassador Awards. The Technology award went to Tina Woytkeilo, Editor of AJM magazine and the Industry Leader Award to Apollonius Nooten-Boom II. Dr. John Wright received the Applied Engineering Award and Stewart Grice was given the Award for Collaborative Research.

The Proceedings of this 19th Annual Santa Fe Symposium have been edited by Eddie Bell and published by Met-Chem Research, P.O. Box 67347, Albuquerque, New Mexico 87193-7347. They may be obtained from "The Santa Fe Symposium”, 7500 Bluewater Road NW, Albuquerque, New Mexico 87121-1962, USA; Fax: 0015058393248.

Website: www.santafesymposium.org

e-mail: ct@tbg.riogrande.com 